\title{
LIGA PARA INSTRUCÇÃO POPULAR
}

\begin{abstract}
Ha algum tempo, tive a idea de organizar, com alguns cidadãos patriotas e de boa vontade, uma liga para a instrucção popular e civica, assumpto que hoie occupa a attenção de todos, e do qual tem tractado o grande professor Miguel Couto, merecendo até um de seus notaveis trabalhos ser transcripto nos annaes do nosso Congresso Legislativo. Difficuldades de execução fizeram que ficasse em projecto meu plano. Julgo que pode ter utilidade para as pessoas que no futuro cogitarão do problema o que escrevi ao tempo em que dei meus esforços á patriotica empreza. Eis por que motivo hoje publico meu modestissimo projecto nas paginas da Revista da Faculdade de Direito.
\end{abstract}

JoÃo Arruda

Origem da Liga - A todo momento ouve-se a affirmação de que o povo brasileiro está sem cultura, que não conhece nem as artes, tão adeantadas em outros paizes, nem tem educação civica. Eis o mal, que, longe de ser negado, é, pelo contrario, reconhecido por toda gente, a cada passo. Qual porém o remedio? Parecer-nos encontrado na diffusão dos conhecimentos na massa popular por meio do livro e da revista. Disseminação de livros e de jornaes em todas as classes sociaes, cremos, será o remédio especifico da molestia já tão conhecida. Na educação, a nosso ver, dois escopos devem ser os da Liga: 1.. habilitação technica, tornando o cidadão apto, não só para prover a subsistencia, mas tambem para o aperfeiçoamento no ramo 
a que se dedicar; e 2. educação moral e civica, de maneira a tornar o cidadão capaz de influir no destino da patria.

Organização - Occorreu-nos a formação, num centro populoso, como é ésta capital, de um nucleo de homens votados aos interesses de seus concidadãos, podendo ter o gremio filiaes, ou, diversamente, associações formarem-se congeneres, mas sem dependencia da estabelecida nesta capital, comquanto obedecendo á mesma orientação. Não só nas cidades mais importantes de nosso Estado seria possivel o estabelecimento de taes nucleos de cultura popular, mas ainda nos mais modestos logarejos.

O Processo. - A idéa fundamental de nossa Liga é a possibilidade da cultura por meio do livro. Desde que se consiga, pela escola primaria, o ensino da leitura, da escripta e das operações fundamentaes da Arithmetica, ter-se-á alcançado um cidadão apto para se desenvolver em todas as sciencias e artes, um homem capaz tambem de formar uma idéa do que seja melhor na direç̧ão dos negocios publicos. Assim, e em summa, entendemos que basta a escola primaria e a disseminação do livro, ou da revista.

Seja-nos permittido fazer algumas considerações sobre esse genero de estudo que é sardonicamente denominado livresco, e que representa, no seculo actual, como de algum modo já representava no anterior, a unica fonte de todo o progresso humano. Na Edade Média, particularmente na Italia, e até mesmo no seculo XVII, foram conservados secretos os processos industriaes. A imprensa veio tornar quasi impossivel esse segredo, de modo que os livros e os periodicos vulgarizam todos os segredos dos industriaes. E' interessante observar que, emquanto era difficil aprender o processo secreto para se alcançar um producto, todos os homens luctavam por esse segredo, ao passo que hoje 
quando o livro tudo traz, despreza-se esse vehiculo comparado por Macleod aos navios que conduzem riquezas ás partes do mundo mais distantes. A instrucção meramente primaria, sem o complemento da profissional, é comparavel, segundo Huxley, em seus discursos sobre a educação, a ministrar a uma pessoa um talher sem que se line forneçam as iguarias. Cumpre fique bem accentuado que seja meramente propedeutica da educação profissional a que é dada na escola primaria, è que deve ser reduzida á leitura, á escripta e aos rudimentos da Arithmetica. Impossivel é ter um professor apto para attender a qualquer vocação que manifeste o alumno. E' ao alumno que cumpre hoje procurar os livros em que poderá se instruir no ramo de conhecimentos para que sentir inclinação. Confiar ao professor a educação civica é tudo quanto ha de mais perigoso. Os factos demonstram que se limitará elle, nem outra coisa é de esperar, a eninar seu discipulo aquillo que o pae de Tasso, com tanta infelicidade, obrigou o filho a fazer: adular os poderosos.

Comparando-se o livro á escola, não é licito dizer o que affirmou Victo Hugo, ao comparal-o aos monumentos: "Ceici tuera cela" A escola tem de superior ao livro tornar muitissimo mais facil a aprendizagem. Quem póde frequentar uma escola não deverá, é certo, recorrer ao ensino de livros, innegavelmente muito menos perfeito, e em que o estudioso consumirá muito mais tempo. Mas o livro tem sobre a escola dois pontos de superioridade. Em 1..$^{\circ}$ logar, está elle prompto para servir ao pohre, áquelle que não póde frequentar as escolas, que não tem junto de si os professores de que necessita. Em 2..$^{\circ}$ logar, dá elle meios de se aprofundar o curioso no assumpto em que pretende especializar-se, e é acompanhado pelo periodico, que traz o especialista informado do progresso do ramo de conhecimentos a que se dedica. 
ExecuÇão do Plano. - Como porém collocar entre as mãos do brasileiro pobre os livros de que elle necessita? Como o esclarecer sobre as revistas que o habilitarão a vir occupar logar honroso entre os seus companheiros? 0 moço que no sertão deseja estudar não tem hoje outro alvitre sinão, com sacrificio seu ou de parentes e amigos, procurar um centro de actividade onde encontre escolas e mestres. E' remedio a este estado de coisas que desejamos dar. Nas cidades, fóra uma illusoria diminuição de horas de trabalho e defeituosissimas escolas nocturnas, nada se fez pelo pobre.

Os processos dos encyclopedistas do seculo XVIII, que tão profundamente impressionaram a nobreza de então, levando-a mesmo a encerrar Morrelet na Bastilha, e a açuJar o infamissimo sabujo Palissot contra os grandes patriotas, pouco valor teriam hoje. A encyclopedia, além Aisto, era obra burgueza, e não de penetração nas últimas e mais humildes camadas sociaes, que hoje occupam a attenção dos intellectuaes. Fez muito a pleiade de D'Alemhert e Diderot, mas não foi completa sua obra. A imprensa desenvolveu-se de modo assombroso no decurso do seculo XIX, e todos os ramos de conhecimento tiveram seus segredos archivados em livros e revistas, verdadeiros depósitos em que se enthesouram a sabedoria dos seculos passados, nossa preciosa herança. Já quando estudava a origem da liberdade americana, fazia Tocqueville sentir que era o jornal lido nas florestas pelos rudes cidadãos que tinham militado sob a bandeira de Washington: era ésta instrucção civica recebida pelos homens que, num momento de repouso, deixavam o machado com que derribavam a floresta para lerem os jornaes, era essa disseminação de principios de educação civica pelo precioso vehiculo denominado revista ou periodico que constituia o principal factor da instituição do self government da livre patria de Jefferson, self government que todos os povos invejam, 
mas que não querem conquistar com a pertinacia e com os sacrificios dos norteamericanos.

Só mesmo com a existencia de um centro de intellê. ctuaes em um nucleo populoso, como é a nossa capital, e com o auxilio de gremios em centros menores é que o estudióso poderá encontrar as informações necessarias para a rota que deverá dar aos seus esforços e para a escolha dos livros e revistas queı deverá lêr.

Vamos traçar o nosso programma para tornar uma realidade nosso ideal.

Programma - Multiplas são as funcções que póde ter o circulo de intellectuaes nesta capital, e grande auxilio receberá, sem duvida, dos centros menores que o eslarecerão sobre as condições locaes, só conhecidas das pessoas afastadas da capital.

Quanto á fundação de escolas ou á alphabetização do povo, multipla será a aç̧ão da nossa Liga. Junto do Governo, terá de informar, usando do direito de representação, sobre o modo de ser ministrada a instrucção primaria ou propedeutica; de indicar os logares em que podem ser situadas com vantagem as escolas; esclarecer acerca das vantagens das escolas ambulantes e temporarias. Junto dos cidadãos, dos paes de familia, será util prégando a necessidade da instrucção, mostrando as vantagens dos estudos, patenteando que não são elles investigações meramente theoricas, sem nenhum alcance pratico. Isto poderá ser feito em conferencias populares, por meio da imprensa, que penetra nas camadas mais humildes da sociedade, que é o pão dos operarios. Emfim junto dos professores primarios agirá indicando-lhes, respeitados os preceitos legaes, quaes os melhores processos, os mais modernos systemas para rapidamente habilitarem o alumno a, por si só, aper. feiçoar-se quando tiver para unico auxilio o livro.

Junto das autoridades locaes, trabalhará incitando-as á creação e subvenção de escolas. 
Junto dos particulares, especialmente junto dos industriaes, dos fazendeiros, dos chefes de quaesquer emprezas mesmo das jornalisticas (as que menos devem necessitar de nossas licções) luctará para que, por um movimento de solidariedade humana, estabeleçam, para seus empregados, escolas primarias, ou, ao menos, proponham-se auxilial-as; quando creadas por outros particulares, proprietarios de emprezas mais rendosas.

Eis quanto á instruoção primaria.

O ensino technico é, em nosso paiz, tudo quanto ha de mais rudimentar. $\mathbf{O}$ menor inquerito sobre o modo por que é ministrado causa verdadeiro desanimo em quantos patriotas desejam ver nossa patria rica e poderosa. E' dessa imperfeição do ensino profissional que provem a inferioridade de nossa industria, verdadeira fonte de riso para as outras nações, er motivo de pena para quantos estremecem o Brasil. Força é confessar que os livros, mesmo no estrangeiro, em assumptos de technica (fóra os de Chimica Industrial), muito deixam ainda a desejar. Ha entretanto, no pouco que se tem escripto, sufficiente para elevar nossa industria, Si os livros são poucos e de qualidade inferior, importantissimas são as revistas.

Quando impossibilitados de frequentar escolas profissionaes, poderão os estudiosos valer-se desses imperfeitos livros e das revistas, que sãa muito proveitosas, como acabamos de dizer. Não estão porém os livros de technologia e revistas ao alcance de todas as bolsas. Dahi a necessidade da fundação de bibliothecas e gabinetes de leitura, embora modestissimos. O ponto mais embaraçoso é o relativo a serem quasi só escriptos em lingua estrangeira quasi todos os tratados (aliás pouco valiosos) sobre technologia. Sería acto de patriotismo lembrar a Liga ao nosso Governo a vantagem da traduoção de livros desse genero para o vernaculo feita por profissionaes habilitados. Não faltam em nossas repartições publicas homens para 
os quaes seria isto empreza summamente facil. Ha um elevado numero de engenheiros brasileiros que poderiam ser incumbidos da traducção das mais importantes obras estrangeiras para uso popular.

Até agora temos dado nossa attenção ao ponto de vista economico, considerando mesmo o homem, o cidadão como sendo um elemento de producção, uma maquina de fazer riquezas. Mas non solum pane vivit homo. Cumpre dar a maior attenção á educação moral e civica, tão descurada ultimamente. Acabou-se com o ensino religioso, em que predominava, é certo, o estudo dos deveres do homem para com Deus, mas em que tambem se dava importancia ás relações com o proximo. Hoje a Moral foi mesmo banida dos exames officiaes, e os seus adversarios dizem que fica aos cuidados da familia. Mas que familia? Quem a educa para que ella possa educar os que amanhan serão cidadãos? Neste particular, é opulenta a literatura livresca. A Moral representa nelles o producto da observação dos seculos. Está estratificada em camadas que o pó dos annos não poude atacar, mas que conserva como resultado das experiencias de nossos avós. Facil é assimilar nos livros o que tem sido mais proveitoso ao homem, ao individuo e á conservação dos Estados. A sciencia, com um estudo frio da Historia, com a analyse de como certos modos de agir deram em resultado a conservação e melhoramento das condições de vida dos povos e dos individuos, estabeleceu, em bases solidissimas, os preceitos que vivifi. cam a applicação do Direito, levando um grande pensador a affirmar que a Moral é o lubrificador do Direito, assim como outrora se perguntou "quid leges sine moribus" Os classicos livros de Smiles, por exemplo (já traduzidos para o portuguez) elevam o caracter do joven, dão-lhe a necessaria coragem para a vida. As obras que contêm a biographia dos varões illustres, dos martyres da liberdade, da sciencia, do patriotismo, levam por este sentimento da imi- 
tação (um dos mais importantes), o joven patriota a deixar o sanchismo, que vae dominando na sociedade moderna, evidentemente em crise de moral e de civismo no momento historico actual. E' neste assumpto que todo o esforço de nossa Liga será proveitosissimo e efficacissimo.

Eis, em seus traços geraes, a Liga para a educação popular para a qual pedimos as forças de todos os bons cidadãos.

Jỗo .ArRuda. 